\title{
Prognostic and predictive value of Ki-67 in triple-negative breast cancer
}

\author{
Wei Wang ${ }^{1, *}$, Jiayi Wu ${ }^{1, *}$, Peifeng Zhang ${ }^{2}$, Xiaochun Fei ${ }^{3}$, Yu Zong ${ }^{1}$, Xiaosong Chen ${ }^{1}$, \\ Ou Huang ${ }^{1}$, Jian-Rong He ${ }^{1}$, Weiguo Chen ${ }^{1}$, Yafen Li ${ }^{1}$, Kunwei Shen ${ }^{1}$, Li Zhu ${ }^{1}$ \\ ${ }^{1}$ Comprehensive Breast Health Center, Ruijin Hospital, Shanghai Jiaotong University School of Medicine, Shanghai 200025, \\ P.R. China \\ ${ }^{2}$ Department of Information Engineering, Shanghai Jiaotong University, Shanghai, 200240, P.R. China \\ ${ }^{3}$ Pathology Department, Ruijin Hospital, Shanghai Jiaotong University School of Medicine, Shanghai 200025, P.R. China \\ *These authors contributed equally to this work
}

Correspondence to: Li Zhu, e-mail: zhuli8@hotmail.com

Keywords: breast carcinoma, hormonal receptor negativity, human epithelial growth factor receptor 2 negativity, proliferation index, platinum

Received: January 09, $2016 \quad$ Accepted: April 09, $2016 \quad$ Published: April 28, 2016

\section{ABSTRACT}

This study was to investigate the prognostic role of Ki-67 in further classification of triple negative breast cancer (TNBC), and to test whether high expression level of Ki67 can predict benefit from carboplatin. From January 2004 to December 2012, 363 patients operated for TNBC were identified through the institutional clinical database. After a median follow-up time of 34 months (5.2-120.0 months), 62 patients (17.1\%) had relapses and 33 patients $(9.1 \%)$ died of breast cancer. In univariate analysis, high Ki-67 index as well as larger tumor size and lymph node involvement was associated with shorter disease-free survival (DFS) and overall survival (OS). In multivariate analysis, high Ki67 is an independent risk factor for DFS (Risk Ratio, RR: 2.835, 95\% confidence interval, 95\% CI: $1.586-5.068, P<0.001$ ) and OS (RR: 3.180, 95\% CI: $1.488-6.793, P=0.003$ ). When analyzing the 3-year DFS by Ki-67 distribution, Subpopulation Treatment Effect Pattern Plot analysis showed a beneficial effect of carboplatin in patients with high Ki-67 index. In conclusion, TNBC is probably a heterogeneous disease with different characteristics and prognosis, and may be further subdivided according to the Ki-67 expression levels. Patients in the high Ki-67 group seem to benefit more from treatment with carboplatin, but this needs to be further verified.

\section{INTRODUCTION}

Triple negative breast cancer (TNBC) is a subgroup of breast cancer lacking estrogen receptor (ER) and progesterone receptor $(\mathrm{PR})$ expression as well as human epithelial growth factor receptor 2 (HER2) amplification. From the histological perspective, TNBC is a common immunohistochemical (IHC) status for a number of tumors with heterogeneous clinical presentations [1]. Recent study identified six TNBC subtypes that display unique profiles [2]. Given the biological diversity within TNBC, it is essential to identify subtypes with a better prognosis which may be spared intensive adjuvant therapy, and those in greatest need of more aggressive regiments.
Tumor proliferative activity, an important cellular function, is closely related to tumor behavior in breast cancer [3]. Various techniques have been developed to assess the proliferation rates, including mitotic count, estimation of the cell fraction in S-phase of cell cycle and IHC determination of proliferation-associated antigens. $\mathrm{Ki}-67$ is one of the most widely used IHC proliferation antigen and has been confirmed as an independent predictive and prognostic factor in early breast cancer $[4,5]$. The value of Ki-67 is an important parameter in sub-classifying luminal tumors into a good prognosis luminal A subgroup and a poor prognosis luminal B subgroup according to St Gallen International Expert Consensus [6]. While the prognostic value of the Ki-67 level in TNBC is yet unclear. 
Treatment for TNBC has been challenging. TNBC is generally considered to exhibit a more aggressive clinical behavior and higher risk of tumor relapse and mortality $[7,8]$ compared with its nontriplenegative counterparts. Besides, the absence of well-defined molecular targets makes it worse and the only treatment strategy is cytotoxic agents. Platinum salt is one of the emerging agents in the treatment of TNBC. Many investigators have explored the role of cisplatin and carboplatin for the treatment of TNBCs in neo-adjuvant and metastatic setting [9-14], while the addition of carboplatin in early stage disease still lacks strong evidence. One important question is whether all TNBC patients need to be exposed to carboplatin, with its toxic effects and high rate of treatment discontinuation; or whether all patients with TNBC would benefit similarly from a platinum salt $[2,15]$.

The aim of this study was to investigate the role of $\mathrm{Ki}-67$ in further classification of TNBC into subtypes with different prognosis, and whether the expression level of Ki-67 can predict benefit of TNBC from carboplatin in adjuvant setting.

\section{RESULTS}

A total of 363 TNBC patients were included in this study. Median age was 55 years (range 23-86). Two hundred and seventy five patients (75.8\%) underwent mastectomy; 324 (89.3\%) patients received chemotherapy. Chemotherapy regimens included EC (Epirubicin $100 \mathrm{mg} / \mathrm{m}^{2}$ IV day 1, Cyclophosphamide $600 \mathrm{mg} / \mathrm{m}^{2}$ IV day 1 , cycled every 21 days for 4 cycles), EC-T (Epirubicin $100 \mathrm{mg} / \mathrm{m}^{2}$ IV day 1, Cyclophosphamide $600 \mathrm{mg} / \mathrm{m}^{2} \mathrm{IV}$ day 1 , cycled every 21 days for 4 cycles followed by Docetaxel $100 \mathrm{mg} / \mathrm{m}^{2}$ IV on day 1 , cycled every 21 days for 4 cycles), TEC (Docetaxel $75 \mathrm{mg} / \mathrm{m}^{2} \mathrm{IV}$ day 1, Epirubicin $75 \mathrm{mg} / \mathrm{m}^{2} \mathrm{IV}$ day 1, Cyclophosphamide $600 \mathrm{mg} / \mathrm{m}^{2} \mathrm{IV}$ day 1 , cycled every 21 days for 6 cycles), TC (Docetaxel $75 \mathrm{mg} / \mathrm{m}^{2} \mathrm{IV}$ day 1 , Cyclophosphamide $600 \mathrm{mg} / \mathrm{m}^{2} \mathrm{IV}$ day 1 , cycled every 21 days for 4 cycles), EC-wPCb (Epirubicin $100 \mathrm{mg} / \mathrm{m}^{2}$ IV day 1 , Cyclophosphamide $600 \mathrm{mg} / \mathrm{m}^{2}$ IV day 1 , cycled every 21 days for 4 cycles followed by Paclitaxel $75 \mathrm{mg} / \mathrm{m}^{2}$ IV day 1 , Carboplatin $2 \cdot 0$ area under curve, cycled every week for 12 cycles) and $\mathrm{wPCb}$ (Paclitaxel $75 \mathrm{mg} / \mathrm{m}^{2}$ IV day 1, Carboplatin 2.0 area under curve, cycled every week for 12 cycles). Regimens containing both anthracycline and taxanes were used in 177 patients $(48.8 \%)$ and $58(16.0 \%)$ patients received platinum-containing regimen. One hundred and seventy one patients $(47.1 \%)$ received radiotherapy.

Out of 363 triple negative tumors, 317 (87.3\%) were histologically identified as invasive ductal carcinomas, $17(4.7 \%)$ as apocrine carcinomas, 9 (2.5\%) as medullary carcinomas, $7(1.9 \%)$ as metaplastic carcinomas, $2(0.6 \%)$ as invasive lobular carcinomas, $3(0.8 \%)$ as neuroendocrine carcinoma, $3(0.8 \%)$ as invasive papillary carcinoma, $2(0.6 \%)$ as adenocystic carcinoma, $1(0.3 \%)$ as myoepithelial carcinoma, $1(0.3 \%)$ as malignant phyllodes tumor and $1(0.3 \%)$ as mucinous carcinoma.

The median Ki-67 expression level was 40\%. With $40 \%$ as the cutoff value of $\mathrm{Ki}-67$ index, 196 patients $(54.0 \%)$ were classified as $\mathrm{Ki}-67$ low expression and 167 patients $(46.0 \%)$ as high expression. Patients' characteristics in association with Ki-67 expression level are described in Table 1. High expression level of Ki- 67 in TNBC was more common in IDC compared with non-IDC $(p<0.001)$ and was associated with younger age $(p<0.001)$ and higher tumor grade $(p<0.001)$. The correlation between tumor size $(p=0.177)$, lymph node metastasis $(p=0.136)$ and Ki-67 expression level is not significant. More patients in Ki-67 high-expression subgroup received chemotherapy $(p=0.007)$.

After a median follow-up time of 34.0 months (5.2-120.0 months), 62 first events were observed (17.1\%), with $24(12.2 \%)$ in $\mathrm{Ki}-67$ low-expression level group and $38(22.8 \%)$ in high-expression level group $\left(\mathrm{X}^{2}=11.372\right.$, $p=0.001)$. The 62 first events included 53 relapses with 30 locoregional recurrences and 44 distant metastases and 9 other events with 6 contralateral breast cancers. All the locoregional recurrence lesions and contralateral breast lesions were proved by using either fine needle aspiration or core needle biopsy. Thirty-three patients (9.1\%) died during the follow-up time and Ki-67 high expression patients had a higher rate of death $\left(13.2 \%\right.$ vs $5.6 \%, X^{2}=13.368$, $p<0.001)$. Meanwhile, high Ki-67 index was significantly associated with poorer 3-year DFS $(90.8 \%$ vs $78.4 \%$ Logrank $p=0.001$; Figure 1A) and OS (98.0\% vs 90.4\% Logrank $p=0.000$; Kaplan-Meier Curve Figure 1B).

In univariate analysis, only high Ki-67 expression, larger tumor size, lymph node positivity were associated with shorter DFS and OS, while other clinical pathological characteristics, such as age, histological subtype and tumor grade did not influence the prognosis. In the multivariate analysis, Ki-67 is an independent prognostic factor for DFS (Risk Ratio, RR: 2.835, 95\% confidence interval, 95\% CI: 1.586-5.068, $P<0.001)$ and OS (RR: 3.180, 95\% CI: $1.488-6.793, P=0.003)$. Results from the univariate analysis and final multivariate Cox regression model are presented in Table 2A, 2B.

When analyzing the 3-year DFS by Ki-67 distribution, STEPP analysis showed a possible beneficial effect of Carboplatin in patients with highly proliferative tumor (Ki-67 > 40\%) (Figure 2A). Figure 2B and Figure 2C present the observed DFS proportion respectively for patients with "high" and "low" Ki-67, stratified by treatment group. In patients with low Ki-67 breast cancer, the use of carboplatin adds little, if any, benefit to the 3 -year DFS (HR: 0.608, 95\% CI: 0.176-2.103). However, patients in the high Ki-67 group seems have a remarkable better 3 -year DFS rates when treated with carboplatin (HR: 0.478, 95\% CI: 0.279-0.819). The interaction between Ki-67 and treatment was not statistically significant $(p=0.346)$. 
Table 1: Correlation of Ki-67 and patient characteristics

\begin{tabular}{|c|c|c|c|}
\hline Characteristics & $\begin{array}{c}\text { Low Ki-67 } \\
\text { N (\%) }\end{array}$ & $\begin{array}{c}\text { High Ki-67 } \\
\text { N (\%) }\end{array}$ & $P$-value \\
\hline$\overline{\text { Age }}$ & & & 0.000 \\
\hline$\leq 55$ & $83(42.3 \%)$ & $106(63.5 \%)$ & \\
\hline$>55$ & $113(57.7 \%)$ & $61(36.5 \%)$ & \\
\hline Histology & & & 0.000 \\
\hline IDC & $159(81.1 \%)$ & $158(94.6 \%)$ & \\
\hline Non-IDC & $37(18.9 \%)$ & $9(5.4 \%)$ & \\
\hline Tumor size $(\mathrm{cm})$ & & & 0.177 \\
\hline $\mathrm{T} 1$ & $98(50.0 \%)$ & $73(43.7 \%)$ & \\
\hline $\mathrm{T} 2$ & $78(39.8 \%)$ & $82(49.1 \%)$ & \\
\hline T3-4 & $20(10.2 \%)$ & $12(7.2 \%)$ & \\
\hline ALN status & & & 0.136 \\
\hline N0 & $138(70.4 \%)$ & $105(62.9 \%)$ & \\
\hline N1 & $21(10.7 \%)$ & $30(18.0 \%)$ & \\
\hline $\mathrm{N} 2$ & $28(14.3 \%)$ & $20(12.0 \%)$ & \\
\hline N3 & $9(4.6 \%)$ & $12(7.2)$ & \\
\hline Tumor Grade & & & 0.000 \\
\hline $\mathrm{I}$ & $27(13.8 \%)$ & $3(1.8 \%)$ & \\
\hline II & $116(59.2 \%)$ & $48(28.7 \%)$ & \\
\hline III & $53(27.0 \%)$ & $116(69.5 \%)$ & \\
\hline Breast surgery & & & 0.175 \\
\hline Mastectomy & $154(78.6 \%)$ & $121(72.5 \%)$ & \\
\hline Lumpectomy & $42(21.4 \%)$ & $46(27.5 \%)$ & \\
\hline Chemotherapy & & & 0.007 \\
\hline Yes & $167(85.2 \%)$ & $157(94.0 \%)$ & \\
\hline No & $29(14.8 \%)$ & $10(6.0 \%)$ & \\
\hline Radiotherapy & & & 0.361 \\
\hline Yes & $88(44.9 \%)$ & $83(49.7 \%)$ & \\
\hline No & $108(55.1 \%)$ & $84(50.3 \%)$ & \\
\hline
\end{tabular}

\section{DISCUSSION}

TNBC is a group of tumors with poor prognosis because of aggressive tumor biology and lack of targeted agents [16]. Better understanding of its biological behavior is essential to improve the outcomes for TNBC patients. In this study, we retrospectively reviewed 363 patients to analyze the correlation between Ki-67 expression level with clinicopathological characteristics and prognosis of TNBC. All the patients coming from one center ensured that the test quality of pathological biomarkers and treatment decision are basically stable.

The use of Ki-67 as a prognostic marker in breast cancer has been widely investigated, but only a few studies have investigated it in the triple negative subgroup [17-19].
Some researchers [18] explored the prognostic value of $\mathrm{Ki}-67$ in the whole cohort of breast cancer, but the number of cases in TNBC and Her2+ classes was quite small and this may limit the ability of Ki-67 to identify clinically distinct subclasses. A Korean group [19] study showed that in preoperative setting, a high Ki-67 expression ( $\geq$ $10 \%$ ) was significantly associated with poor relapse-free survival and overall survival in TNBC in spite of a higher pathologic complete response (pCR) rate. Munzone et al [20] reported that Ki-67 labeling index was associated with different prognosis subgroups in node-negative TNBC with a cut-off value of $35 \%$. In line with these results, our study found that high expression of Ki-67 (> 40\%) is significantly correlated with a worse prognosis in TNBC patients, irrespective of the tumor size and lymph node status. 
A

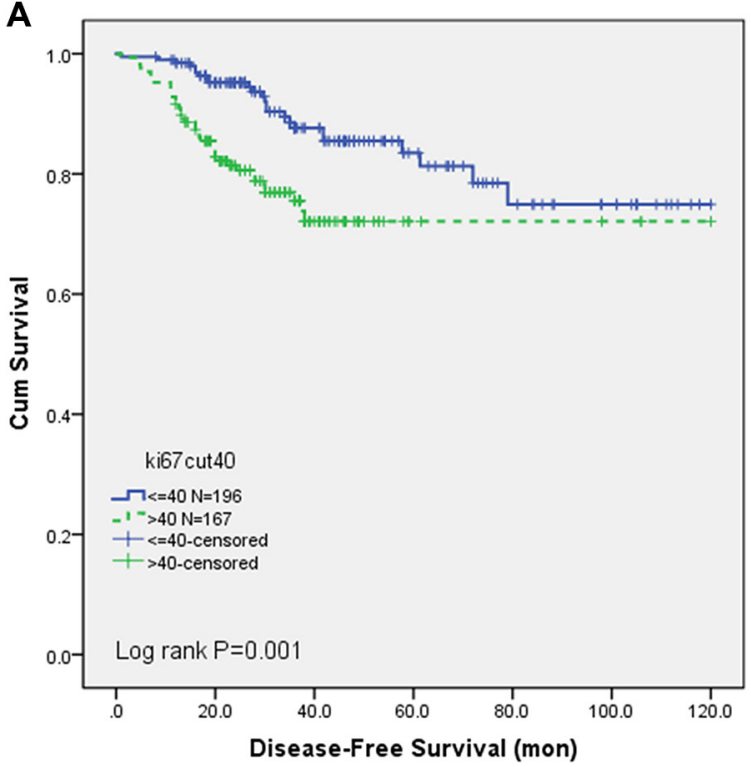

B

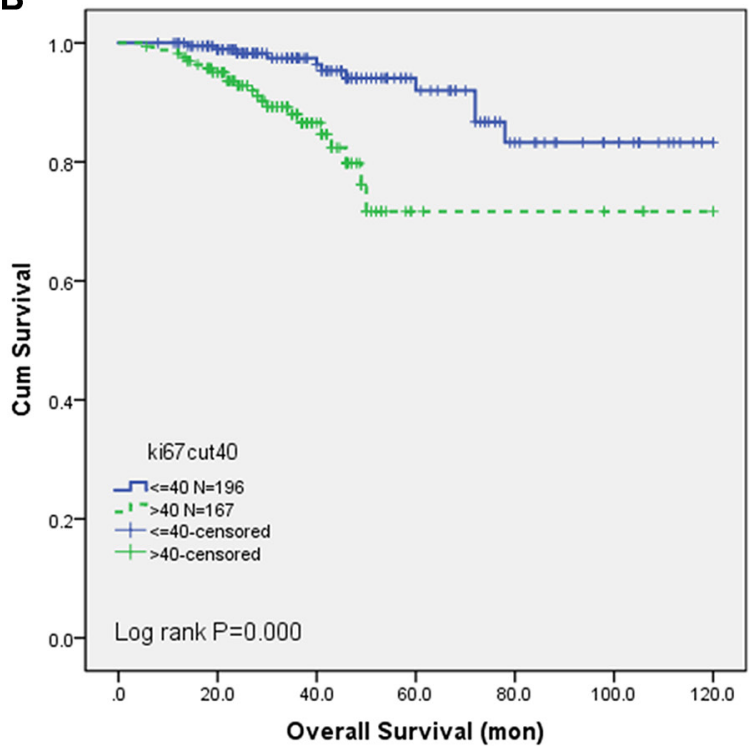

Figure 1: Disease-free survival and overall survival by Ki-67 expression level. (A) The 3-year DFS was significantly better in low Ki-67 group than in the high Ki-67 group (90.8\% vs 78.4\% Log-rank $p=0.001)$ and (B) A poorer 3-year OS was also detected in high Ki-67 group $(98.0 \%$ vs $90.4 \%$ Log-rank $p=0.000)$.
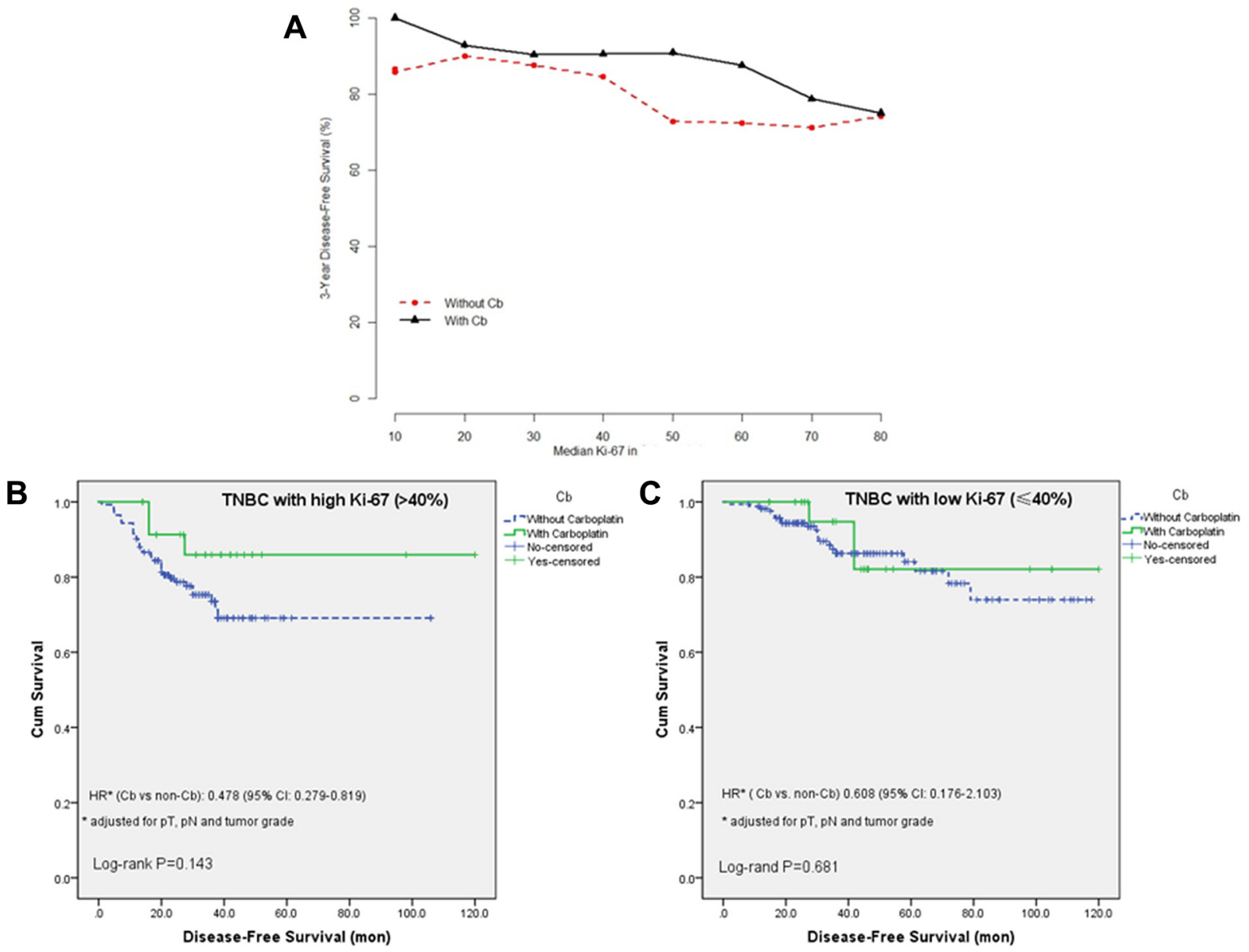

Figure 2: The effect of carboplatin treatment on DFS. (A) Subpopulation Treatment Effect Pattern Plot (STEPP) of 3-year Disease-free survival. (B) Disease-free survival in the high Ki-67 (Ki-67 $>40 \%$ ) group according to carboplatin treatment. (C) Disease-free survival in the low Ki-67 (Ki-67 $\leq 40 \%)$ group according to carboplatin treatment. Univariate log-rank test $p$-values and Hazard Ratios (HR) (carboplatin vs non carboplatin) were reported. 
Table 2A: Multivariate cox regression of DFS

\begin{tabular}{|c|c|c|c|c|}
\hline & \multicolumn{2}{|c|}{ Univariate } & \multicolumn{2}{|c|}{ Multivariate } \\
\hline & HR (95\% CI) & $P$ value & HR $(95 \%$ CI) & $P$ value \\
\hline Tumor size & & 0.026 & & 0.030 \\
\hline $\mathrm{T} 1$ & 1.000 & & 1.000 & \\
\hline $\mathrm{T} 2$ & $2.292(1.234,4.257)$ & 0.009 & $2.226(1.206,4.111)$ & 0.011 \\
\hline T3-4 & $2.321(0.972,5.543)$ & 0.058 & $2.299(0.972,5.437)$ & 0.058 \\
\hline ALN status & & 0.000 & & 0.000 \\
\hline N0 & 1.000 & & 1.000 & \\
\hline $\mathrm{N} 1$ & $2.120(1.046,4.298)$ & 0.037 & $2.084(1.044,4.158)$ & 0.037 \\
\hline $\mathrm{N} 2$ & $1.549(0.657,3.655)$ & 0.317 & $1.628(0.765,3.463)$ & 0.206 \\
\hline N3 & $7.332(2.994,17.960)$ & 0.000 & $7.834(3.589,17.099)$ & 0.000 \\
\hline Grade & & 0.102 & & 0.089 \\
\hline $\mathrm{I}$ & 1.000 & & 1.000 & \\
\hline II & $2.302(0.850,6.335)$ & 0.101 & $2.378(0.873,6.477)$ & 0.090 \\
\hline III & $1.817(0.996,3.313)$ & 0.052 & $1.847(1.015,3.363)$ & 0.045 \\
\hline Ki-67 & & 0.000 & & 0.000 \\
\hline low & 1.000 & & 1.000 & \\
\hline high & $2.952(1.623,5.274)$ & 0.000 & $2.835(1.586,5.068)$ & 0.000 \\
\hline
\end{tabular}

Table 2B: Multivariate cox regression of OS

\begin{tabular}{|c|c|c|c|c|}
\hline & \multicolumn{2}{|c|}{ Univariate } & \multicolumn{2}{|c|}{ Multivariate } \\
\hline & HR $(95 \%$ CI $)$ & $P$ value & HR $(95 \%$ CI $)$ & $P$ value \\
\hline Tumor size $(\mathrm{cm})$ & & 0.009 & & 0.008 \\
\hline $\mathrm{T} 1$ & 1.000 & & 1.000 & \\
\hline $\mathrm{T} 2$ & $4.787(1.753,13.074)$ & 0.002 & $4.855(1.797,13.117)$ & 0.002 \\
\hline T3-4 & $3.508(0.921,13.355)$ & 0.066 & $3.739(1.081,12.935)$ & 0.037 \\
\hline ALN status & & 0.000 & & 0.000 \\
\hline N0 & 1.000 & & 1.000 & \\
\hline N1 & $2.663(0.998,7.105)$ & 0.050 & $2.611(1.021,6.675)$ & 0.045 \\
\hline $\mathrm{N} 2$ & $1.734(0.507,5.933)$ & 0.380 & $1.403(0.484,4.073)$ & 0.533 \\
\hline N3 & $13.878(4.071,47.310)$ & 0.000 & $11.104(4.119,29.935)$ & 0.000 \\
\hline Ki-67 & & 0.004 & & 0.003 \\
\hline low & 1.000 & & 1.000 & \\
\hline high & $3.558(1.488,8.507)$ & 0.004 & $3.180(1.488,6.793)$ & 0.003 \\
\hline
\end{tabular}

Ki-67 measurement by IHC is a low cost method suitable for widespread use in clinical practice [21]. International Ki-67 in Breast Cancer Working Group has proposed guidelines for the analysis, reporting, and use of this potentially important marker based on current evidence [22]. The guidelines were strictly followed in this study, which guaranteed the value of it. In another retrospective study from our center [23], high expression of Ki-67 was correlated with early recurrence in Luminal B/Her2 negative breast cancer, with a cut-off value of $30 \%$. This may reflect the stability and reliability of the test of Ki-67 in one center.

Cut-off points of Ki-67 index employed in clinical trials and studies differed widely [17-18, 20-21], ranged from $10 \%$ to $61 \%$. Since baseline Ki-67 values for triple negative and HER2 positive tumors are much higher than for luminal tumors [18], cut-offs selection of Ki-67 
might be more apparent if it was considered within each subgroups respectively. We selected the median of Ki- 67 as the cut-off value in this study, which was widely adopted in other researches [24]. In view of the inter-observer and across-labs variability, much more evidence is needed to set an appropriate cut-off point of Ki-67 for TNBC.

The follow-up time of our study is relatively short. However, despite of a median 34-month follow-up, Ki-67 expression level shows its independent prognostic value in TNBC. This might be attributed to the early recurrence pattern of TNBC within the first three years of follow-up $[25,26]$. In this study, $94.3 \%(50 / 53)$ relapse occurred in the first three years following the surgery.

A key point for usage of platinum-contained regimen would be the selection of the right patient. There is a well-described association between TNBCs and BRCA germline mutations [27]. Neoadjuvant trials have shown high rates of $\mathrm{pCR}$ among BRCA1-associated breast cancers treated with cisplatin [28]. However, the routine clinical application of BRCA gene tests still has some difficulties. While the test of Ki-67 is more convenient and economical and might be a good alternative.

In GeparSixto clinical trial [10], the addition of neoadjuvant carboplatin to a taxane-anthracycline regimen significantly increases the pCR proportion of TNBC patients. Subgroup analysis showed that Odds radio favor carboplatin in high Ki-67 group (>20\%) is 1.40 (95\%CI: 0.968-2.02), higher than in the low Ki-67 group (OR: 1.09, 95\% CI: 0.490-2.4). Similarly, our study showed a possible beneficial effect of carboplatin in patients with highly proliferative tumor (Ki-67>40\%) in the adjuvant setting. But this trend still needs to be verified in further prospective, well-balanced studies with large sample size.

One possible limitation of this study could be related to the heterogeneity of the adjuvant treatment, as not all patients received the same regimen. However, we can assess that among the patients who received chemotherapy, the majority $(72.5 \%)$ received an anthracycline-containing regimen and more than half of them $(55.6 \%)$ received regimens containing both anthracycline and taxanes.

In conclusion, TNBC seems to be a heterogeneous group with different clinical outcomes. TNBC with high proliferation potential should be followed-up more frequently within three years, and might be a candidate for additional postoperative treatments with different mechanisms, such as carboplatin.

\section{MATERIALS AND METHODS}

\section{Patients}

We collected information on consecutive breast cancer patients undergoing breast surgery between January 2004 and December 2012 in Shanghai Ruijin Hospital through the breast cancer database at the Comprehensive Breast Health Center. The protocol was approved by the
Ethical Committees of Shanghai Ruijin Hospital and all the patients provided their written informed consents to participant this study before the clinical and pathological data were collected.

A total of 363 TNBC patients were retrospectively investigated. The baseline data including age, tumor characteristics (tumor size, lymph node metastasis, distant metastasis, tumor grade, pathological stage, ER/PR/HER2 expression and histological type) and surgical information were retrieved. Treatment decision for every patient was made by daily multidisciplinary meeting that was attended by surgeons, medical oncologists, radiation oncologists, and pathologists.

\section{Pathology methods}

Tumors were classified histologically according to the World Health Organization Classification of Tumors [29]. Histological grade was evaluated according to Elston and Ellis scoring system [30]. IHC staining of ER, PR, HER2 and Ki-67 was routinely carried out by using Ventana BenchMark XT system (Ventana Medical Systems, Tucson, AZ). IHC staining was performed on 4- $\mu$ m slices of formalin-fixed paraffin-embedded (FFPE) tissue sections with primary antibodies against ER (SP1, 1:100, Dako, Denmark), PR (PgR 636, 1:100, Dako, Denmark), HER2 (4B5,Roche, Switzerland), Ki-67(MIB-1, 1:100, Dako, Denmark). IHC expression of HER2 was scored as follows: 0 (no staining or faint membrane staining), 1+ (faint membrane staining in $>10 \%$ of tumor cells, incomplete membrane staining), 2+ (weak to moderate membrane staining in $>10 \%$ of tumor cells), and $3+$ (uniform, intense membrane staining of $>30 \%$ of invasive tumor cells). A Fluorescence in situ hybridization (FISH) test for HER2 gene amplification was routinely ordered when HER2 was IHC 2+. FISH was performed using the PathVysion HER-2 DNA FISH Kit (Vysis Inc, Downers Grove, IL) according to the manufacturer's instructions.

All histologic and IHC tumor slides were evaluated by two pathologists. Histological grades and all biological features were evaluated based on the invasive components.

The cutoff for ER positivity and PR positivity was $1 \%$ positive tumor cells with nuclear staining [31]. Positive for HER2 was either IHC HER2 $3+$ or FISH amplified (ratio of HER2 to CEP17 of $\geq 2.0$ or average HER2 copy number $\geq 6.0$ signals/cell) [32]. The Ki67 index was expressed as the percentage of positively nuclear staining cells among at least 1000 invasive cells in the area scored. Staining intensity was not relevant [22].

\section{Follow-up and statistical analysis}

Breast cancer relapse was defined as the first proven invasive local/contralateral breast, regional, or distant recurrence in any site [33]. The disease-free survival (DFS) was defined as the interval from the date of the primary surgery to the first relapse, second primary non- 
breast invasive cancer or death attributable to any cause. Overall survival (OS) was defined as the time from the date of primary surgery to the time of death regardless of breast cancer related or not.

All $p$ values less than 0.05 were considered to indicate statistical significance. All statistical tests were two-sided, with the confidence interval of $95 \%$. Chi-Square test was employed for categorized variables (Fisher's exact test when the Chi-square test was unavailable). Survival curves were plotted by Kaplan-Meier method. Log-rank test was used to determine the associations between individual variables and survival, logistic regression modeling to examine the association of tumor features with Ki-67 expression level and Cox proportional hazards regression analyses to identify significant prognostic factors in TNBC. Statistical analyses were carried out in SPSS version 17.0 (SPSS, Inc., Chicago, IL).

Interaction between use of carboplatin and $\mathrm{Ki}-67$ was graphically evaluated by use of Subpopulation Treatment Effect Pattern Plot (STEPP) methodology [34]. Briefly, the STEPP method uses a sliding-windows approach to define several overlapping subpopulations of patients according to a continuous covariate, such as $\mathrm{Ki}-67$, and plots the resulting treatment effects estimated within each subpopulation. The STEPP analyses were carried out with the R (http://cran.r-project.org/) software with Package 'STEPP'.

\section{ACKNOWLEDGMENTS AND FUNDING}

This study was funded by National Natural Science Foundation of China 81572581. The funders had no role in study design, data collection and analysis, decision to publish, or preparation of the manuscript. This investigation was presented as poster discussion in the EMSO Asia 2015 Congress, December 18-21, 2015, Singapore.

\section{CONFLICTS OF INTEREST}

The authors have no conflicts of interest to declare.

\section{REFERENCES}

1. Hernandez-Aya LF, Chavez-Macgregor M, Lei X, MericBernstam F, Buchholz TA, Hsu L, Sahin AA, Do KA, Valero V, Hortobagyi GN, Gonzalez-Angulo AM. Nodal status and clinical outcomes in a large cohort of patients with triple-negative breast cancer. J Clin Oncol. 2011; 29:2628-2634. doi: 10.1200/JCO.2010.32.1877.

2. Lehmann BD, Bauer JA, Chen X, Sanders ME, Chakravarthy AB, Shyr Y, Pietenpol JA. Identification of human triple-negative breast cancer subtypes and preclinical models for selection of targeted therapies. J Clin Invest. 2011; 121:2750-67. doi: 10.1172/JCI45014.
3. Daidone MG, Silvestrini R. Prognostic and predictive role of proliferation indices in adjuvant therapy of breast cancer. J Natl Cancer Inst Monogr. 2001; 30:27-35.

4. Urruticoechea A, Smith IE, DowsettM. Proliferation marker Ki67 in early breast cancer. J Clin Oncol. 2005; 23:7212-7220.

5. Viale G, Regan MM, Mastropasqua MG, Maffini F, Maiorano E, Colleoni M, Price KN, Golouh R, Perin T, Brown RW, Kovács A, Pillay K, Ohlschlegel C, et al. Predictive value of tumor Ki-67 expression in two randomized trials of adjuvant chemoendocrine therapy for node-negative breast cancer. J Natl Cancer Inst. 2008; 100:207-12. doi: 10.1093/jnci/djm289.

6. Goldhirsch A, Winer EP, Coates AS, Gelber RD, PiccartGebhart M, Thürlimann B, Senn HJ; Panel members. Personalizing the treatment of women with early breast cancer: highlights of the St Gallen International Expert Consensus on the Primary Therapy of Early Breast Cancer 2013. Ann Oncol. 2013; 24:2206-2223. doi: 10.1093/ annonc/mdt303.

7. Carey LA, Perou CM, Livasy CA, Dressler LG, Cowan D, Conway K, Karaca G, Troester MA, Tse CK, Edmiston S, Deming SL, Geradts J, Cheang MC, et al. Race, breast cancer subtypes, and survival in the Carolina Breast Cancer Study. JAMA. 2006; 295:2492-2502.

8. Blows FM, Driver KE, Schmidt MK, Broeks A, van Leeuwen FE, Wesseling J, Cheang MC, Gelmon K, Nielsen TO, Blomqvist C, Heikkilä P, Heikkinen T, Nevanlinna H, et al. Subtyping of breast cancer by immunohistochemistry to investigate a relationship between subtype and short and long term survival: a collaborative analysis of data for 10,159 cases from 12 studies. PLoS Med. 2010; 7:e1000279. doi: 10.1371/journal.pmed.1000279.

9. Chang HR, Glaspy J, Allison MA, Kass FC, Elashoff R, Chung DU, Gornbein J. Differential response of triplenegative breast cancer to a docetaxel and carboplatin-based neoadjuvant treatment. Cancer. 2010; 116:4227-37. doi: 10.1002/cncr.25309.

10. von Minckwitz G, Schneeweiss A, Loibl S, Salat C, Denkert C, Rezai M, Blohmer JU, Jackisch C, Paepke S, Gerber B, Zahm DM, Kümmel S, Eidtmann H, et al. Neoadjuvant carboplatin in patients with triple-negative and HER2-positive early breast cancer (GeparSixto; GBG 66): a randomised phase 2 trial. Lancet Oncol. 2014; 15:747-56. doi: 10.1016/S1470-204570160-3.

11. Sikov WM, Berry DA, Perou CM, Singh B, Cirrincione CT, Tolaney SM, Kuzma CS, Pluard TJ, Somlo G, Port ER, Golshan M, Bellon JR, Collyar D, et al. Impact of the addition of carboplatin and/or bevacizumab to neoadjuvant once-per-week paclitaxel followed by dose-dense doxorubicin and cyclophosphamide on pathologic complete response rates in stage II to III triple-negative breast cancer: CALGB 40603 (Alliance). J Clin Oncol. 2015; 33:13-21. doi: 10.1200/JCO.2014.57.0572. 
12. Maisano R, Zavettieri M, Azzarello D, Raffaele M, Maisano M, Bottari M, Nardi M. Carboplatin and gemcitabine combination in metastatic triple-negative anthracycline- and taxane-pretreated breast cancer patients: a phase II study. J Chemother. 2011; 23:40-43.

13. Carey LA, Rugo HS, Marcom PK, Mayer EL, Esteva FJ, Ma CX, Liu MC, Storniolo AM, Rimawi MF, Forero-Torres A, Wolff AC, Hobday TJ, Ivanova A, et al. TBCRC 001: randomized phase II study of cetuximab in combination with carboplatin in stage IV triple-negative breast cancer. J Clin Oncol. 2012; 30:2615-23. doi: 10.1200/JCO.2010.34.5579.

14. Hurley J, Reis IM, Rodgers SE, Gomez-Fernandez C, Wright J, Leone JP, Larrieu R, Pegram MD. The use of neoadjuvant platinum-based chemotherapy in locally advanced breast cancer that is triple negative: retrospective analysis of 144 patients. Breast Cancer Res Treat. 2013; 138:783-94. doi: 10.1007/s10549-013-2497-y.

15. Mayer IA, Abramson VG, Lehmann BD, Pietenpol JA. New strategies for triple-negative breast cancer-deciphering the heterogeneity. Clin Cancer Res. 2014; 20:782-90. doi: 10.1158/1078-0432.

16. Gluz O, Liedtke C, Gottschalk N, Pusztai L, Nitz U, Harbeck N. Triple-negative breast cancer-current status and future directions. Ann Oncol. 2009; 20:1913-1927. doi: 10.1093/annonc/mdp492.

17. Keam B, Im SA, Lee KH, Han SW, Oh DY, Kim JH, Lee SH, Han W, Kim DW, Kim TY, Park IA, Noh DY, Heo DS, Bang YJ. Ki-67 can be used for further classification of triple negative breast cancer into two subtypes with different response and prognosis. Breast Cancer Res. 2011; 13:R22. doi: 10.1186/bcr2834.

18. Aleskandarany MA, Green AR, Benhasouna AA, Barros FF, Neal K, Reis-Filho JS, Ellis IO, Rakha EA. Prognostic value of proliferation assay in the luminal, HER2 positive and triple negative biological classes of breast cancer. Breast Cancer Res. 2012; 14:R3.

19. Miyashita $M$, Ishida $T$, Ishida $K$, Tamaki $K$, Amari $M$, Watanabe M, Ohuchi N, Sasano H. Histopathological subclassification of triple negative breast cancer using prognostic scoring system: five variables as candidates. Virchows Arch. 2011; 458:65-72. doi: 10.1007/s00428-010-1009-2.

20. Munzone E, Botteri E, Sciandivasci A, Curigliano G, Nolè F, Mastropasqua M, Rotmensz N, Colleoni M, Esposito A, Adamoli L, Luini A, Goldhirsch A, Viale G. Prognostic value of Ki-67 labeling index in patients with node-negative, triple-negative breast cancer. Breast Cancer Res Treat. 2012; 134:277-282. doi: 10.1007/s10549-012-2040-6.

21. Mrklić I, Ćapkun V, Pogorelić Z, Tomić S. Prognostic value of Ki-67 proliferating index in triple negative breast carcinomas. Pathol Res Pract. 2013; 209:296-301. doi: 10.1016/j.prp.2013.02.012.

22. Dowsett M, Nielsen TO, A, Hern R, Bartlett J, Coombes RC, Cuzick J, Ellis M, Henry NL, Hugh JC, Lively T, McShane L, Paik S, Penault-Llorca F, et al. Assessment of Ki67 in breast cancer: recommendations from the International Ki67 in Breast Cancer working group. J Natl Cancer Inst. 2011; 103:1656-1664. doi: 10.1093/jnci/djr393.

23. Zong Y, Zhu L, Wu J, Chen X, Huang O, Fei X, He J, Chen W, Li Y, Shen K. Progesterone receptor status and ki-67 index may predict early relapse in luminal b/her2 negative breast cancer patients: a retrospective study. PloS One. 2014; 9:e95629. doi: 10.1371/journal.pone.0095629.

24. Yerushalmi R, Woods R, Ravdin PM, Hayes MM, Gelmon KA. Ki-67 in breast cancer: prognostic and predictive potential. Lancet Oncol. 2010; 11:174-183. doi: 10.1016/ S1470-204570262-1.

25. Dent R, Trudeau M, Pritchard KI, Hanna WM, Kahn HK, Sawka CA, Lickley LA, Rawlinson E, Sun P, Narod SA. Triple-negative breast cancer: clinical features and patterns of recurrence. Clin Cancer Res. 2007; 13:4429-4434.

26. Liedtke C, Mazouni C, Hess KR, André F, Tordai A, Mejia JA, Symmans WF, Gonzalez-Angulo AM, Hennessy B, Green M, Cristofanilli M, Hortobagyi GN, Pusztai L. Response to neoadjuvant therapy and long-term survival in patients with triple negative breast cancer. J Clin Oncol. 2008; 26:1275-1281. doi: 10.1200/JCO.2007.14.4147.

27. Billar JA, Dueck AC, Stucky CC, Gray RJ, Wasif N, Northfelt DW, McCullough AE, Pockaj BA. Triple negative breast cancers: unique clinical presentations and outcomes. Ann Surg Oncol. 2010; 3:384-90. doi: 10.1245/s10434010-1260-4.

28. Byrski T, Gronwald J, Huzarski T, Grzybowska E, Budryk M, Stawicka M, Mierzwa T, Szwiec M, Wisniowski R, Siolek M, Dent R, Lubinski J, Narod S. Pathologic complete response rates in young women with BRCA1-positive breast cancers after neoadjuvant chemotherapy. J Clin Oncol. 2010; 28:375-9. doi: 10.1200/JCO.2008.20.7019.

29. Tavassoli F, Devilee P. Pathology and genetics of tumors of the breast and female genital organs. Lyon, 2003; France: IARC Press

30. Elston CW, Ellis IO. Pathological prognostic factors in breast cancer, I: the value of histological grade in breast cancer: experience from a large study with long-term follow-up. Histopathology. 2002; 41:154-61.

31. Hammond ME, Hayes DF, Dowsett M, Allred DC, Hagerty KL, Badve S, Fitzgibbons PL, Francis G, Goldstein NS, Hayes M, Hicks DG, Lester S, Love R, et al. American Society of Clinical Oncology/College of American Pathologists guideline recommendations for immunohistochemical testing of estrogen and progesterone receptors in breast cancer. J Clin Oncol. 2010; 28:2784-2795. doi: 10.1200/JCO.2009.25.6529.

32. Wolff AC1, Hammond ME, Hicks DG, Dowsett M, McShane LM, Allison KH, Allred DC, Bartlett JM, Bilous M, Fitzgibbons P, Hanna W, Jenkins RB, Mangu PB, et al. Recommendations for human epidermal growth factor receptor 2 testing in breast cancer: American Society of Clinical Oncology/College of American Pathologists clinical practice guideline update. J Clin Oncol. 2013; 31:3997-4013. doi: 10.1200/JCO.2013.50.9984. 
33. Hudis CA, Barlow WE, Costantino JP, Gray RJ, Pritchard KI, Chapman JA, Sparano JA, Hunsberger S, Enos RA, Gelber RD, Zujewski JA. Proposal for standardized definitions for efficacy end points in adjuvant breast cancer trials: the STEEP system. J Clin Oncol. 2007; 25:2127-2132.
34. Bonetti M, Gelber RD. A graphical method to assess treatment-covariate interactions using the Cox model on subsets of the data. Stat Med. 2000; 19:2595-609. 